Egypt. J. of Appl. Sci., 36 (7-8) 2021

\title{
SENSITIVITY ANALYSIS OF A MATHEMATICAL MODEL FOR MICROBIAL DESALINATION CELLS
}

Merna Heshama $^{a}$; Abdelsalam Elawwadb ${ }^{\text {b }}$; Ahmed Mekawy ${ }^{\text {c }}$ and Mohamed Hamdy Nour ${ }^{\text {a }}$

a Irrigation and Hydraulics Engineering Dept., Faculty of Engineering, Cairo University, El-Gamaa St., 12613 Giza, Egypt.

b Environmental Engineering Dept., Faculty of Engineering, Cairo University, ElGamaa St., 12613 Giza, Egypt.

c Sanitary and Environmental Engineering Institute, Housing and Building National Research Center, 87 Tahir St., 11511 Dokki, Giza, Egypt.

'E-mail - aabd_ekmaguid@yahoo.com

Key Words: Microbial Desalination cell - Mathematical model - Energy -Desalination-Wastewater treatment

\section{ABSTRACT}

Microbial Desalination Cell (MDC) is new developed technology that treats wastewater, generate electrical energy from it and desalinate saline water. However, this complicated technology faces many challenges to be implemented on a large scale that's why mathematical modelling for MDC is very essential. In this paper, A previous complex mathematical model was studied. Sensitivity analysis was conducted for model parameters to evaluate the influence of each parameter on the dynamics of MDC including electric current, desalination and COD removal to increase understanding of the relationships between input and output parameters in the model. Based on sensitivity results, the top effective parameters controlling the performance of MDC are maximum anodophilic microorganisms growth rate, maximum substrate consumption rate by anodophilic microorganisms and mediator yield.

\section{INTRODUCTION}

Bioelectrochemical systems (BES) are systems that their function is wastewater treatment and energy recovery through converting chemical energy embedded in wastewater to electrical energy through microbial-electrochemical reactions [1]. Microbial desalination cell (MDC) is one of bio electrochemical system types that desalinate salty water using current generated from oxidation of organic matter so it achieves three main goals: energy production, wastewater treatment and desalination [2].MDCs concept of operation is similar to electrodialysis desalination technology, however it uses electrical energy converted from chemical energy in wastewater [3]. Since BES are complicated 
systems , comprehensive mathematical models is important to understand the dynamic relation between physical, chemical, biological and electrochemical processes, so BES modelling is essential step towards optimization and scaling up [4] . However, Few MDC models are reported in the literature [5]. Ping Model is a MDC model with many parameters that increases the complexity of the model. In this paper, A sensitivity analysis was conducted for the parameters of Ping Model to determine the effect of each parameters on the MDC performance. The analysis was conducted using MATLAB and results of the most important parameters are presented.

\section{Mass Balances for Substrate}

Materials and Methods (MDC Model[6])

The following equations shows the mass balance for the substrate concentration in anode chamber

$$
\begin{aligned}
& \frac{\mathrm{d} S}{\mathrm{dt}}=-\mu_{\mathrm{s}, \mathrm{a}} \mathrm{C}_{\mathrm{a}}-\mu_{\mathrm{s}, \mathrm{m}} \mathrm{C}_{\mathrm{m}}+\text { Danode }(\operatorname{Sin}-\mathrm{S}) \\
& \mu_{\mathrm{s}, \mathrm{a}}=\mu_{\mathrm{s}, \mathrm{a}, \max } \frac{\mathrm{S}}{\mathrm{Ka}+\mathrm{S}} \frac{\mathrm{M}_{\mathrm{OX}}}{\mathrm{K}_{\mathrm{M}}+\mathrm{M}_{\mathrm{OX}}} \\
& \mu_{\mathrm{s}, \mathrm{m}}=\mu_{\mathrm{s}, \mathrm{m}, \max } \frac{\mathrm{S}}{\mathrm{Km}+\mathrm{S}} \\
& \quad \text { Danode }=\frac{\mathrm{Qin}}{\text { Vanode }}
\end{aligned}
$$

Where $\mathrm{t}$ is time $(\mathrm{d})$; $\mathrm{S}$ is substrate concentration (mg-S.L-1) ; Sin is influent substrate concentration (mg-S.L-1); $\mathrm{Ca}$ and $\mathrm{Cm}$ are concentrations for anodophilic and methanogenic microorganisms (mg$\mathrm{x} . \mathrm{L}-1) ; \mu_{\mathrm{s}, \mathrm{a}}$ and $\mu_{\mathrm{s}, \mathrm{m}}$ are substrate consumption rate by anodophilic and methanogenic microorganisms (mg-S .mg-x-1 .d-1); Danode is dilution rate in anode chamber (day -1); Qin is the influent flow rate of substrate (L.day-1); Vanode is the volume of anode chamber (L); $\mu_{\mathrm{s}, \mathrm{a}, \max }$ and $\mu_{\mathrm{s}, \mathrm{m} \text {,max }}$ are maximum substrate consumption rate by anodophilic and methanogenic microorganisms (mg-S .mg-x-1 .d-1) ;K,a and K,m are the half saturation constants for anodophilic and methanogenic microorganisms (mg-S.L-1); Mox is oxidized mediator fraction per anodophilic microorganisms (mg-M-mg-a-1); $\mathrm{KM}$ is half saturation constant for mediators (mg-M.L-1).

Mass Balances for Microorganisms

The following equations shows the mass balance for microbial population in anode chamber. The microbial population include 
anodophilic microorganisms that release electrons from consumption of organic matter and methanogenic microorganisms that convert substrate into methane:

$$
\begin{gathered}
\frac{\mathrm{dC}_{\mathrm{a}}}{\mathrm{dt}}=\mu_{\mathrm{a}} \mathrm{C}_{\mathrm{a}}-\mathrm{k}_{\mathrm{d}, \mathrm{a}} \mathrm{C}_{\mathrm{a}}-\alpha_{\mathrm{a}} \mathrm{D}_{\text {anode }} \mathrm{C}_{\mathrm{a}} \\
\frac{\mathrm{d} \mathrm{C}_{\mathrm{m}}}{\mathrm{dt}}=\mu_{\mathrm{m}} \mathrm{C}_{\mathrm{m}}-\mathrm{k}_{\mathrm{d}, \mathrm{m}} \mathrm{C}_{\mathrm{m}}-\alpha_{\mathrm{m}} \mathrm{D}_{\text {anode }} \mathrm{C}_{\mathrm{m}} \\
\mu_{\mathrm{a}}=\mu_{\mathrm{a}, \max } \frac{\mathrm{s}}{\mathrm{Ka}+\mathrm{S}} \frac{\mathrm{M}_{\mathrm{OX}}}{\mathrm{K}_{\mathrm{M}}+\mathrm{M}_{\mathrm{OX}}} \\
\mu_{\mathrm{m}}=\mu_{\mathrm{m}, \max } \frac{\mathrm{S}}{\mathrm{Km}+\mathrm{S}} \\
\alpha_{\mathrm{a}}=\left(\frac{1+\tanh \left(\mathrm{K}_{\mathrm{a}, \mathrm{x}}\left(\mathrm{C}_{\mathrm{a}}+\mathrm{C}_{\mathrm{m}}-\mathrm{C}_{\mathrm{a}, \max }\right)\right)}{2}\right. \\
\alpha_{\mathrm{m}}=\left(\frac{1+\tan \mathrm{h}\left(\mathrm{K}_{\mathrm{m}, \mathrm{x}}\left(\mathrm{C}_{\mathrm{a}}+\mathrm{C}_{\mathrm{m}}-\mathrm{C}_{\mathrm{m}, \max }\right)\right)}{2}\right.
\end{gathered}
$$

Where $\mu \mathrm{a}$ and $\mu \mathrm{m}$ are growth rate of anodophilic and methanogenic microorganisms (d-1); Kd,a and $\mathrm{Kd}, \mathrm{m}$ are decay rates of anodophilic and methanogenic microorganisms; $\mu_{a, \max }$ and $\mu_{m, \max }$ are maximum growth rate of anodophilic and methanogenic microorganisms ( d-1); $\alpha \mathrm{a}$ and $\alpha \mathrm{m}$ are the dimensionless biofilm retention constants ; $\mathrm{Ka}, \mathrm{x}$ and $\mathrm{Km}, \mathrm{x}$ are steepness factors of anodophilic and methanogenic microorganism (L.mg-x-1); $\mathrm{C}$ a,max and $\mathrm{C} \mathrm{m}, \max$ are maximum attainable concentration for anodophilic and methanogenic microorganisms (mgx.L-1)

\section{Mass balance for Mediators}

The intracellular mediator exists either in its oxidized and reduced form. The following equation shows the mass balance for oxidized mediators

$\mathrm{M}$ total$=\mathrm{M}$ red + Mox

$\frac{\mathrm{dMox}}{\mathrm{dt}}=-\mathrm{Y}_{\mathrm{s}, \mathrm{a}}+\gamma \frac{\mathrm{I}_{\mathrm{MDC}}}{\mathrm{neF}} \frac{1}{\mathrm{VCa}}$

Where Mred and Mtotal are reduced and total mediator fraction per anodophilic microorganisms (mg-M.mg-a-1); $\mathrm{Y}$ is the mediator yield (mg-M .mg-S-1); IMDC is the MDC current (A) ; F is faraday constant (A. d. mole-1); $\gamma$ is mediator molar mass (mg-M molmed -1); ne is the number of electrons transferred per mole of mediator (mole-e- .mole 
med -1)

\section{Mass Balance for Salt concentrations}

The following equations shows the mass balance for the salt concentration in the three chambers

$$
\begin{aligned}
& \frac{\mathrm{dCsalt}, \mathrm{m}}{\mathrm{dt}}=\operatorname{Dsalt}(\text { Csalt, in }- \text { Csalt, } \mathrm{m})-\mathrm{d}\left(\mathrm{C}_{\text {salt }, \mathrm{m}}-\mathrm{C}_{\text {salt }, \mathrm{a}}\right) \\
& \quad-\mathrm{d}\left(\mathrm{C}_{\text {salt }, \mathrm{m}}-\mathrm{C}_{\text {salt }, \mathrm{c}}\right)-\frac{\mathrm{I}}{\mathrm{F} \text { Vsalt }} \\
& \frac{\mathrm{dCsalt,a}}{\mathrm{dt}}=\mathrm{d}\left(\mathrm{C}_{\text {salt }, \mathrm{m}}-\mathrm{C}_{\text {salt }, \mathrm{a}}\right) \text {-Danode }(\text { Csalt }, \mathrm{a}) \\
& \frac{\mathrm{dCsalt,c}}{\mathrm{dt}}=\mathrm{d}\left(\mathrm{C}_{\text {salt }, \mathrm{m}}-\mathrm{C}_{\text {salt }, \mathrm{c}}\right) \\
& \text { Dsalt }=\frac{\text { Qsalt }}{\text { Vsalt }}
\end{aligned}
$$

Csalt,a , Csalt,m, and Csalt,c are salt concentrations in anode, salt and cathode chambers (mol-salt.L-1) ; C salt, in is influent salt concentration (mol-salt.L-1) ; d is a membrane salt transfer coefficient (day-1); Dsalt is dilution rate in middle chamber (day -1) ; Q salt is salt flow rate (L.day-1); Vsalt is volume of salt chamber (L

\section{Electrochemical equations}

MDC current was determined by Ohm's law:

$$
\begin{aligned}
& I_{\mathrm{MDC}}=\frac{V_{O C}-\frac{R T}{F} \ln \left(\frac{M_{\text {Total }}}{M_{\text {red }}}\right)}{R_{\text {int }}+R_{\text {ext }}+\text { Rsalt }+ \text { Ranolyte }+ \text { Rmembrane }} \\
& \text { Voc }=\text { Emin }+(\text { Emax }- \text { Emin }) e^{-1 / k_{\mathrm{r}} \mathrm{C}_{a}} \\
& \text { Rint=Rmin+ }(\text { Rmax- Rmin }) e^{-k_{\mathrm{r}} \mathrm{C}_{a}}
\end{aligned}
$$

Where Voc is open circuit voltage (V); Emin and Emax are minimum and maximum observed open circuit voltage (V); Rmin and Rmax are minimum and maximum observed internal resistances $(\Omega)$; $\mathrm{kr}$ is the constant that determines how fast the internal resistance respond to the change in anodophilic microorganisms' concentration $(\mathrm{L} \cdot \mathrm{mg}-\mathrm{a}-1)$. $\mathrm{R}$ is ideal gas constant (J.K-1.mole -1); R salt is resistance of salt solution $(\Omega)$ ; $\mathrm{R}$ membrane is mass transfer resistance through an exchange membrane; Ranolyte is resistance of anolyte solution; Rext is the external resistance

\section{RESULTS AND DISCUSSION}

\section{Base case results}

The model differential-algebraic equations were solved using 
MATLAB and parameters values were determined from previous studies [6], [7]. Substrate consumption increases by anodophilic and methanogenic microorganisms with decreasing rate until it reaches steady state after 8th day. Also, Current increases until it reaches the steady state after 8th day so consequently salt removal from middle chamber increases also with decreasing rate until it becomes constant starting from 8th day.
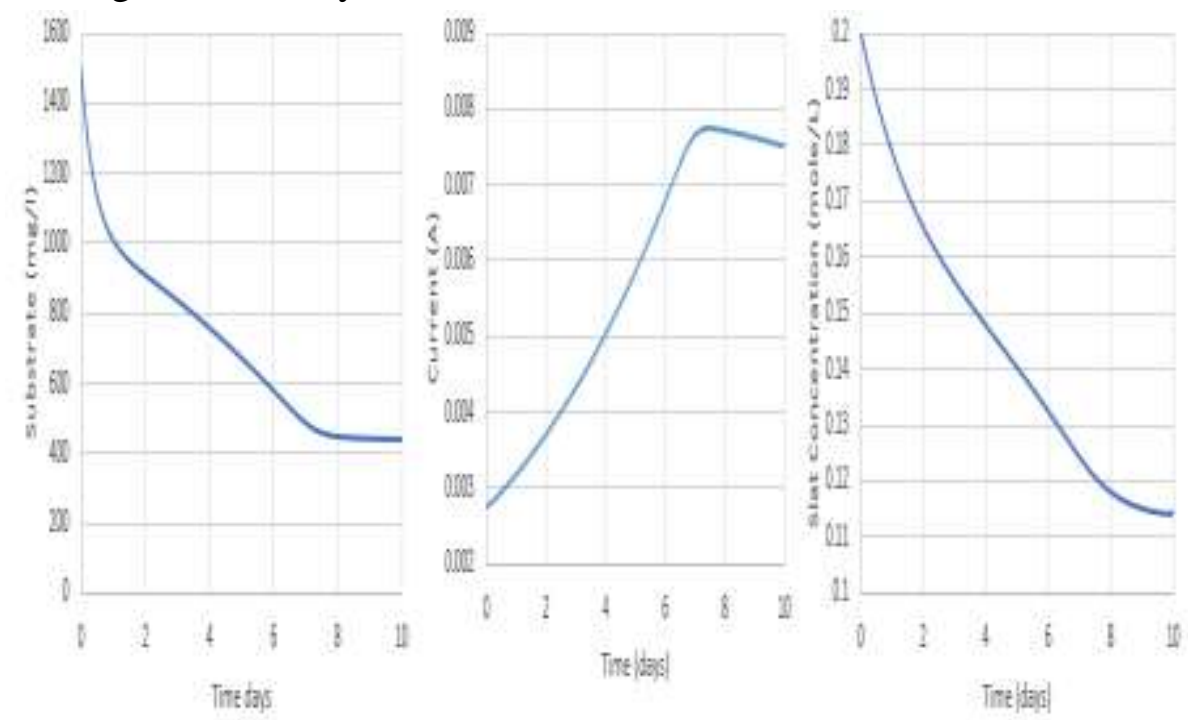

Figure 1 Change of substrate concentration, current produced and salt concentration in desalination chamber with time

\section{Sensitivity analysis}

The sensitivity analysis is conducted for MDC biological, operating and design parameters to determine the effect of parameters on the performance of MDC model. This analysis will use the local relative sensitivity analysis method in which it will be carried out on all parameters one by one by changing one of the parameters, while the other parameters were fixed without any change. Local relative sensitivity analysis [8] was used to determine the effect of changing the parameter value as ratio between change in output value to change in parameters value.

The following equation was used for each parameter:

$$
T_{j}=\frac{P\left(t, x_{j}+\delta x_{j}\right)-P\left(t, x_{j}\right)}{\delta x_{j}} * \frac{x_{j}}{P\left(t, x_{j}\right)}, j=1,2, \ldots
$$

Where the dependent time sensitivity for any parameter ' $\mathrm{j}$ ' is $\mathrm{Tj}$; the output value is $\mathrm{P}$; the value of parameter $\mathrm{j}$ is $\mathrm{xj}$; the change in $\mathrm{xj}$ is $\delta$ $\delta_{\mathrm{xj}}$; 
the step of the change in this study is $\delta$ xj $=0.01 x j$.

3. Sensitivity analysis results

a) Maximum growth rate of microorganisms

The results of sensitivity analysis for the maximum growth rates effect on current, substrate concentration and salt concentration in the middle chamber are shown in Figure 2 . It is clear that anodophilic and methanogenic microorganisms maximum growth rates $(\mu \mathrm{a}, \max$ and $\mu \mathrm{m}$,max) are effectual parameters but methanogenic microorganisms maximum growth rate is less effectual .The increase of anodophilic microorganisms maximum growth rate cause higher rate of substrate consumption so more decrease in substrate concentration until 7 th day then substrate concentration increases due biofilm space limitation.Also, It cause increase in current produced and consequently the salt concentration decreases until 7th day since anodophilic microorganisms produce electrons from consumption of organic matter then after 7th day current produced decreases and salt concentration increases. On the other hand, the increase of methanogenic microorganisms' maximum growth rate cause decrease in substrate concentration and decrease in the current produced as the methanogenic organisms don't produce electrons from substrate oxidation and consequently, salt concentration increases.
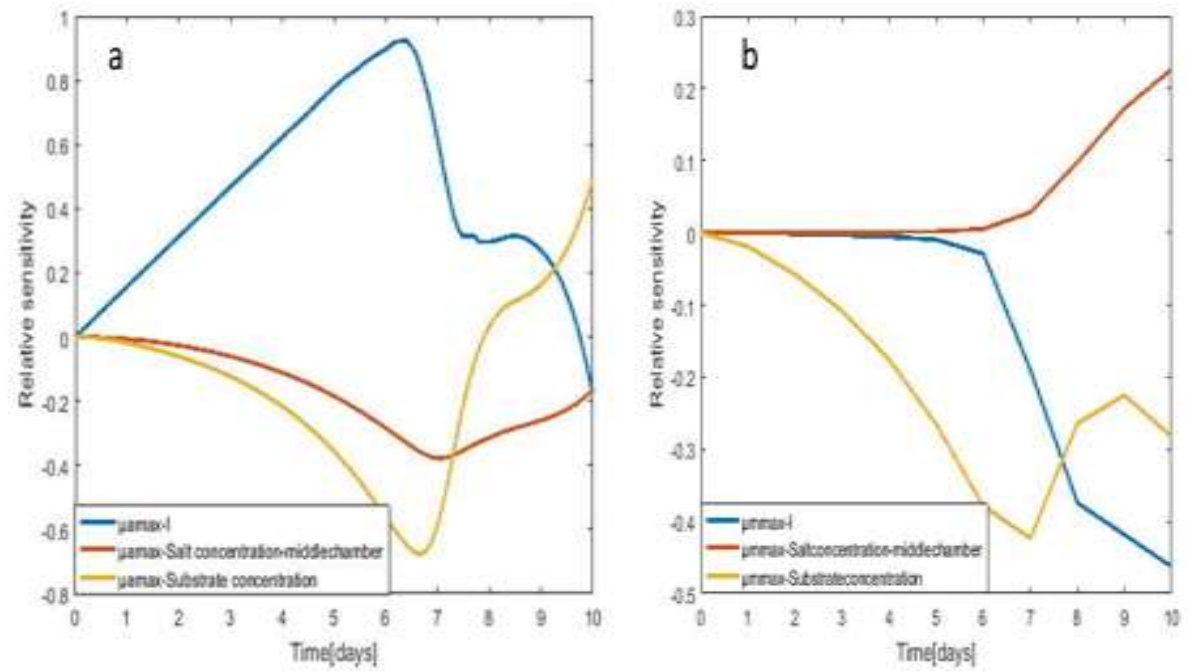

Figure 2 Relative sensitivity of current, substrate concentration and salt concentration in the middle chamber with respect to a) anodophilic maximum growth rates b) methanogenic maximum growth rates 


\section{Half rate constant}

The results of sensitivity analysis for the half rates constant effect on current, substrate concentration and salt concentration in the middle chamber are shown in Figure 3. It is clear that anodophilic microorganisms, methanogenic microorganisms and mediators half rate constant (Ka, Km and $\mathrm{KM}$ ) are effectual parameters but mediators half rate constant is the most effectual. As $\mathrm{Ka}$ increases, anodophilic microorganisms growth rate and substrate consumption rate decrease until 9th day. Due to decrease of anodophilic growth rate, the biofilm space limitation effect is delayed so substrate concentration decrease and current increases from 9th to 10th day. As Km increase, methanogenic microorganisms' growth rate decrease, so substrate concentration increases, current decreases and salt concentration increases. As KM increases, anodophilic microorganisms growth rate and substrate consumption rate decrease, so substrate concentration increase and current decrease that cause increase in salt concentration.
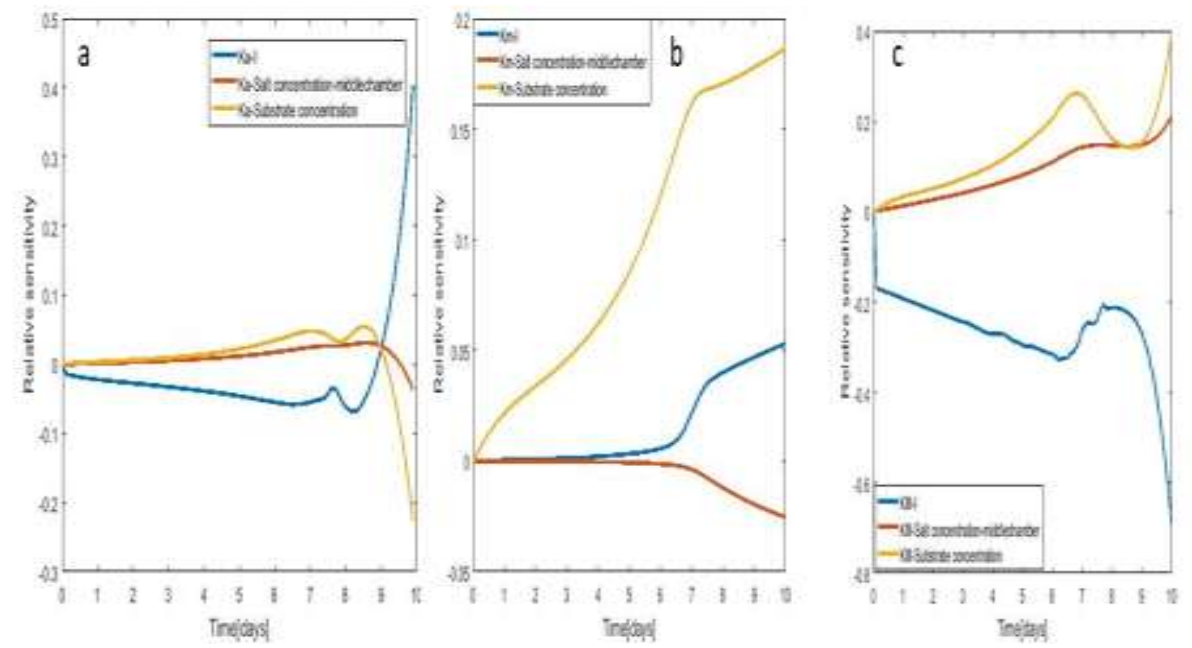

Figure 3 Relative sensitivity of current, substrate concentration and salt concentration in the middle chamber with respect to half rate constant of a) anodophilic microorganisms b) methanogenic microorganisms and c) mediators

\section{Decay rates}

The results of sensitivity analysis for the decay rate effect on current, substrate concentration and salt concentration in the middle chamber are shown in Figure 4 . It is clear that the increase of anodophilic and methanogenic microorganisms decay rate are ineffectual parameters. 

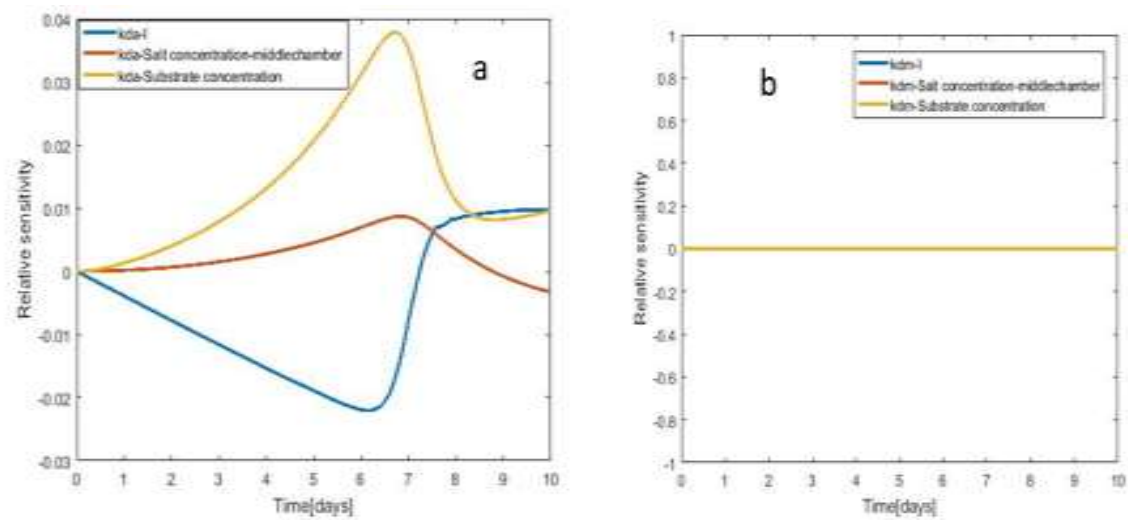

Figure 4 Relative sensitivity of current, substrate concentration and salt concentration in the middle chamber with respect to decay rate of a) anodophilic microorganisms and b) methanogenic microorganisms

\section{Biofilm space limitation}

The results of sensitivity analysis for the biofilm space limitation effect on current, substrate concentration and salt concentration in the middle chamber are shown in Figure 5.It is clear that the anodophilic and methanogenic biofilm space limitation become more effectual from 7 th to 10th day because when space limitation value increases, it allows more increase of anodophilic and methanogenic microorganisms concentration.
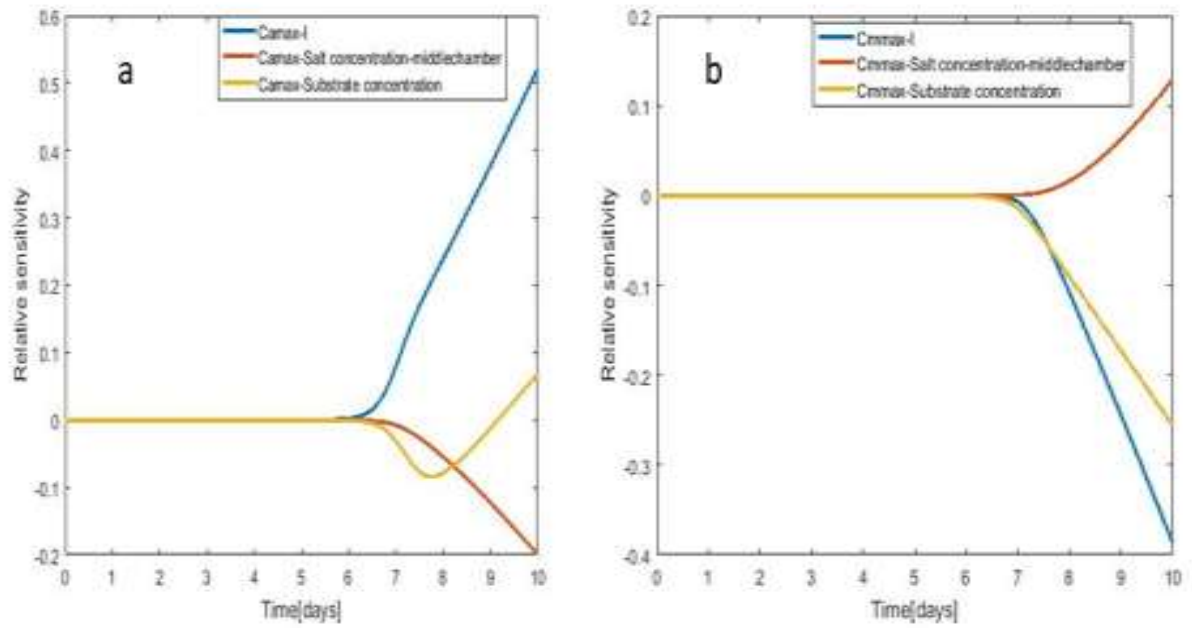

Figure 5 Relative sensitivity of current, substrate concentration and salt concentration in the middle chamber with respect to a) anodophilic biofilm space limitation and b) methanogenic biofilm space limitation 


\section{Maximum substrate consumption rate}

The results of sensitivity analysis for the effect of maximum substrate consumption rate on current, substrate concentration and salt concentration in the middle chamber are shown in Figure 6. The increase of methanogenic maximum substrate consumption rate has no effect on current production or desalination but it increases the rate of substrate oxidation by methanogenic organisms. However, the increase of maximum substrate consumption rate by anodophilic microorganisms cause sharp decrease in substrate concentration. Also, It cause increase in current and consequently decrease in salt concentration as increase of maximum substrate consumption rate reduce oxidized mediators concentration so it cause a decrease in concentration losses that leads to increase in current produced.
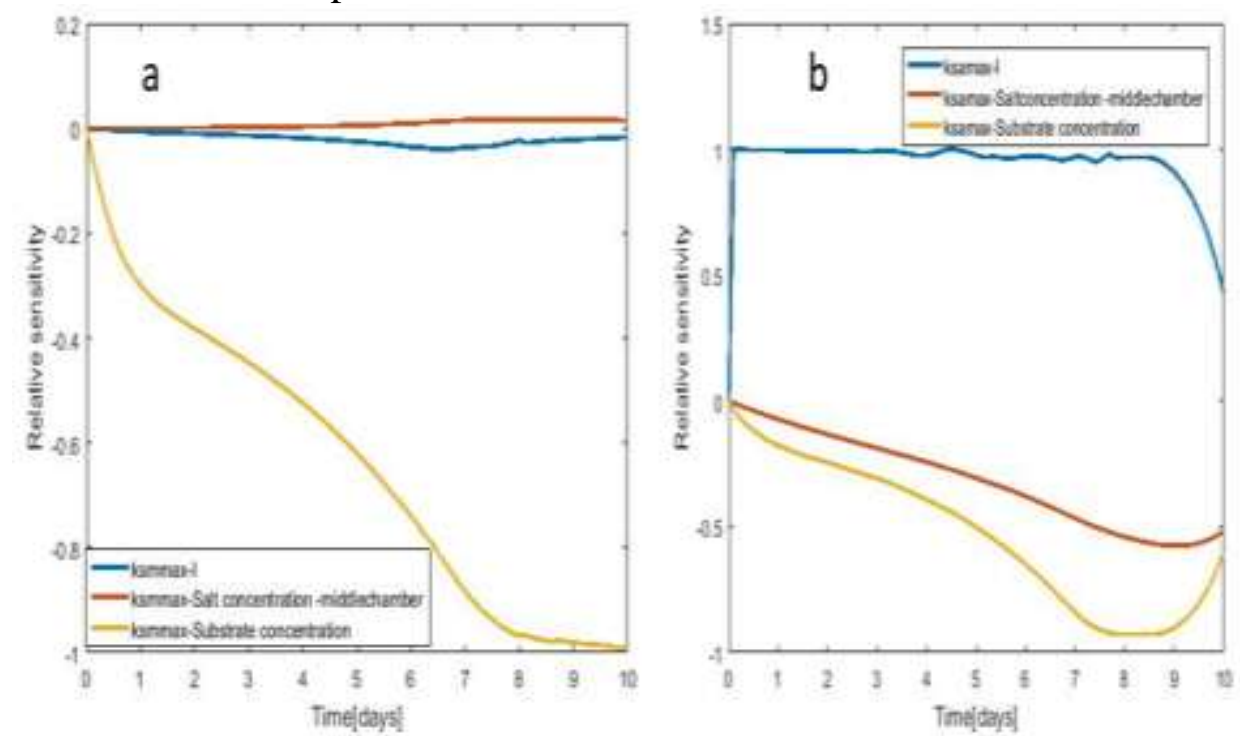

Figure 6 Relative sensitivity of current, substrate concentration and salt concentration in the middle chamber with respect to maximum substrate consumption rate by a) methanogenic microorganisms and b) anodophilic microorganisms

\section{Mediator yield}

The results of sensitivity analysis for the effect of mediator yield on current, substrate concentration and salt concentration in the middle chamber are shown in Figure 7. Concerning the current and salt concentration in middle chamber, it is clear that mediator yield is very effectual parameter as it causes more current production and salt removal but it has minor effect on substrate concentration. 


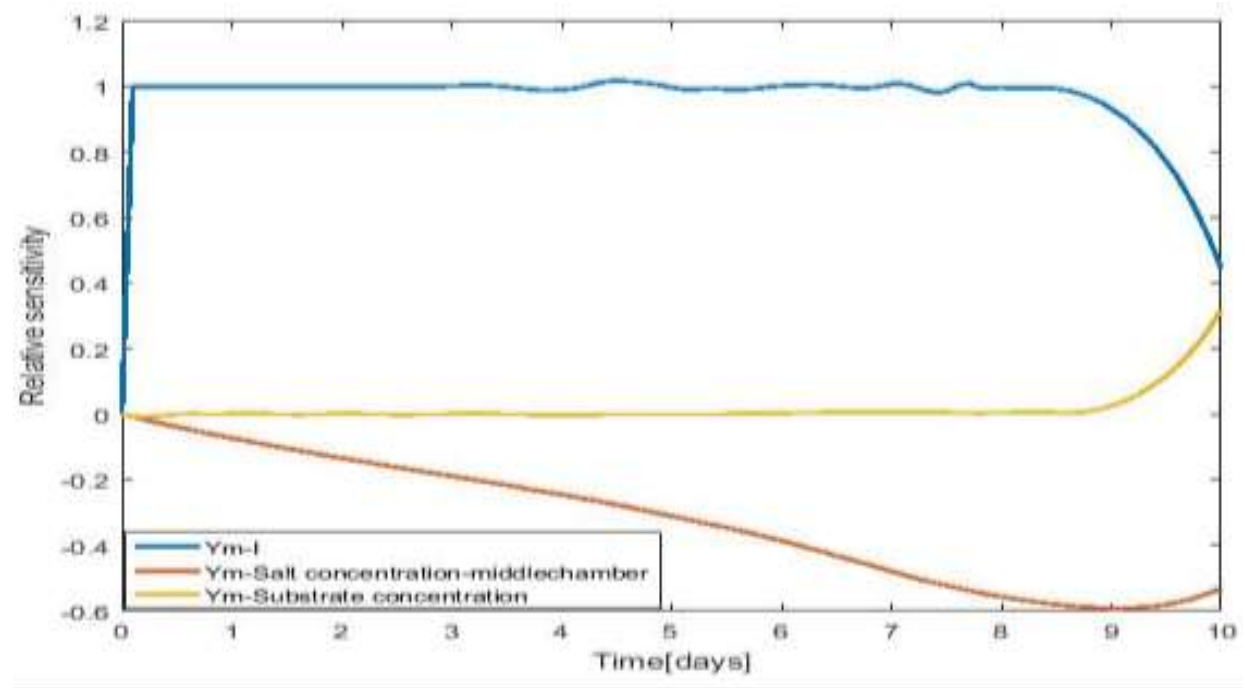

Figure 7 Relative sensitivity of current, substrate concentration and salt concentration in the middle chamber with respect to mediator yield

\section{Diffusion coefficient}

The results of sensitivity analysis for the effect of diffusion coefficient on current, substrate concentration and salt concentration in the middle chamber are shown in Figure 8. It is clear that increase of diffusion coefficient is very effectual only in increasing salt removal in the middle chamber, however it has negligible effect on current.

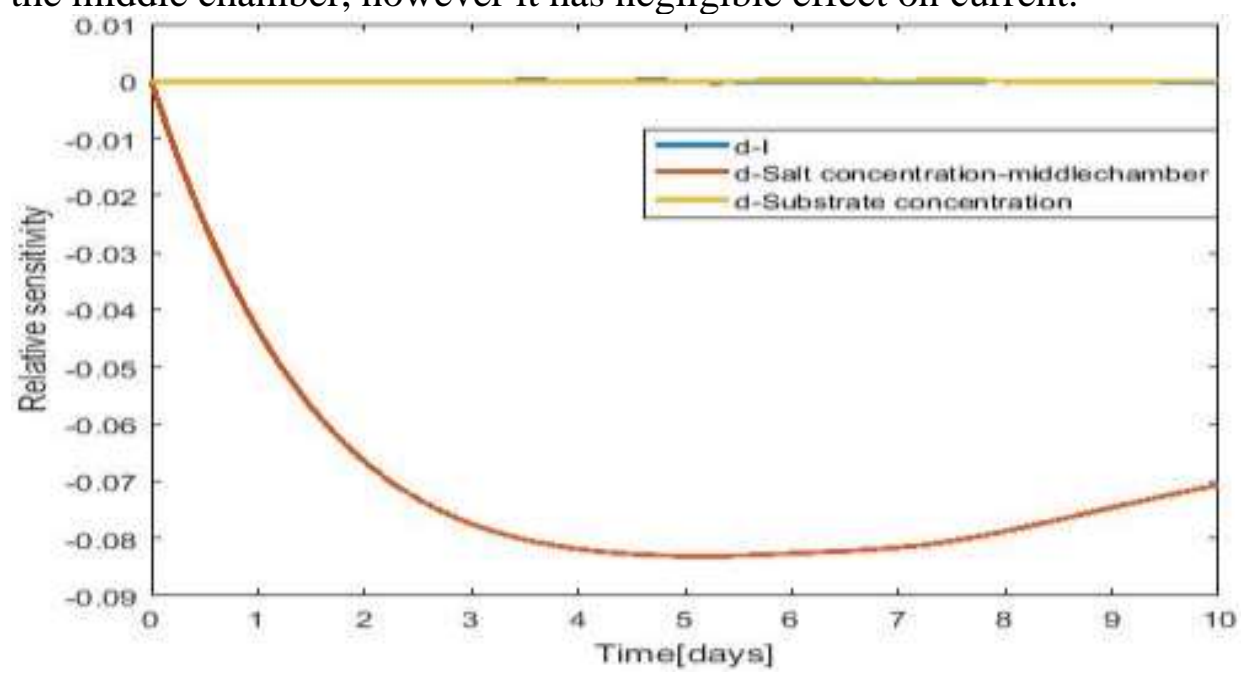

Figure 8 Relative sensitivity of current, substrate concentration and salt concentration in the middle chamber with respect to diffusion coefficient 


\section{Number of electrons transferred per mole of mediator}

The results of sensitivity analysis for the effect of diffusion coefficient on current, substrate concentration and salt concentration in the middle chamber are shown in Figure 8 . It is very clear that number of electrons transferred per mediator is a very effectual parameter.

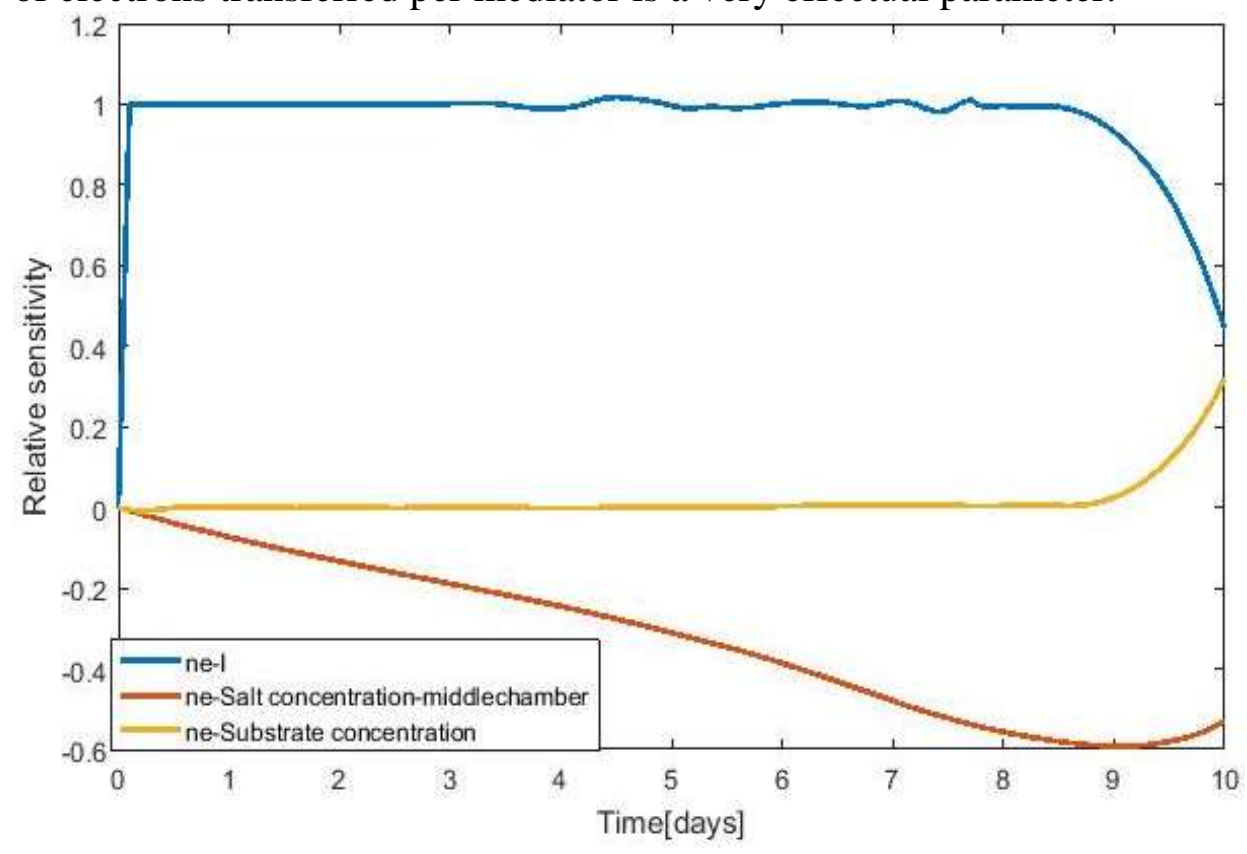

Figure 9 Relative sensitivity of current, substrate concentration and salt concentration in the middle chamber with respect to number of electrons transferred per mole of mediator

\section{CONCLUSION}

In this study, it is very clear that MDC model is very complicated and multivariable system that requires more analysis to be easily understood and used. Sensitivity analysis is one of the important tools that help to understand this system. Sensitivity analysis that was conducted for the MDC model shows the effect of each parameter on the performance of MDC inculding COD removal, desalination and electrical current produced. Top parameters that affect MDC performance are maximum substrate consumption rate by anodophilic microorganis, the maximum growth rate of these microorganisms and mediator yield so model users have to focus on reestimation of these parameters' values for better prediction of results. 


\section{REFERENCES}

[1] Yang, E. ; K.J. Chae ; M.J. Choi ; Z. He and I.S. Kim(2019): "Critical review of bioelectrochemical systems integrated with membrane-based technologies for desalination, energy selfsufficiency, and high-efficiency water and wastewater treatment," Desalination, 452: 40-67.

[2] Elawwad, A. ; D.Z. Husein ; M. Ragab and A. Hamdy(2020): "Enhancing the performance of microbial desalination cells using $\delta \mathrm{MnO} 2 /$ graphene nanocomposite as a cathode catalyst," J. Water Reuse Desalin., 10 (3):214-226.

[3] Xu, C. and et al., (2020): "Simultaneous bioelectricity generation, desalination, organics degradation, and nitrogen removal in aircathode microbial desalination cells," SN Appl. Sci., 2(2):1-11.

[4] Gadkari, S. ; S. Gu and J. Sadhukhan(2018): "Towards automated design of bioelectrochemical systems: A comprehensive review of mathematical models," Chem. Eng. J., 343: 303-316.

[5] Rahman, S. and et al.,(2021): "Towards upscaling microbial desalination cell technology: A comprehensive review on current challenges and future prospects," J. Clean. Prod., 288: 125597.

[6] Ping, Q. ; C. Zhang ; X. Chen ; B. Zhang ; Z. Huang and Z. He(2014): "Mathematical model of dynamic behavior of microbial desalination cells for simultaneous wastewater treatment and water desalination," Environ. Sci. Technol., 48: 13010-13019.

[7] Pinto, R.P. ; B. Srinivasan ; M.F. Manuel and B. Tartakovsky (2010): "A two-population bio-electrochemical model of a microbial fuel cell," Bioresour. Technol., 101(14): 5256-5265 .

[8] Zeng, Y. ; Y.F. Choo ; B.H. Kim and P. Wu (2009): "Modelling and simulation of two-chamber microbial fuel cell," J. Power Sources, 195(1):79-89.

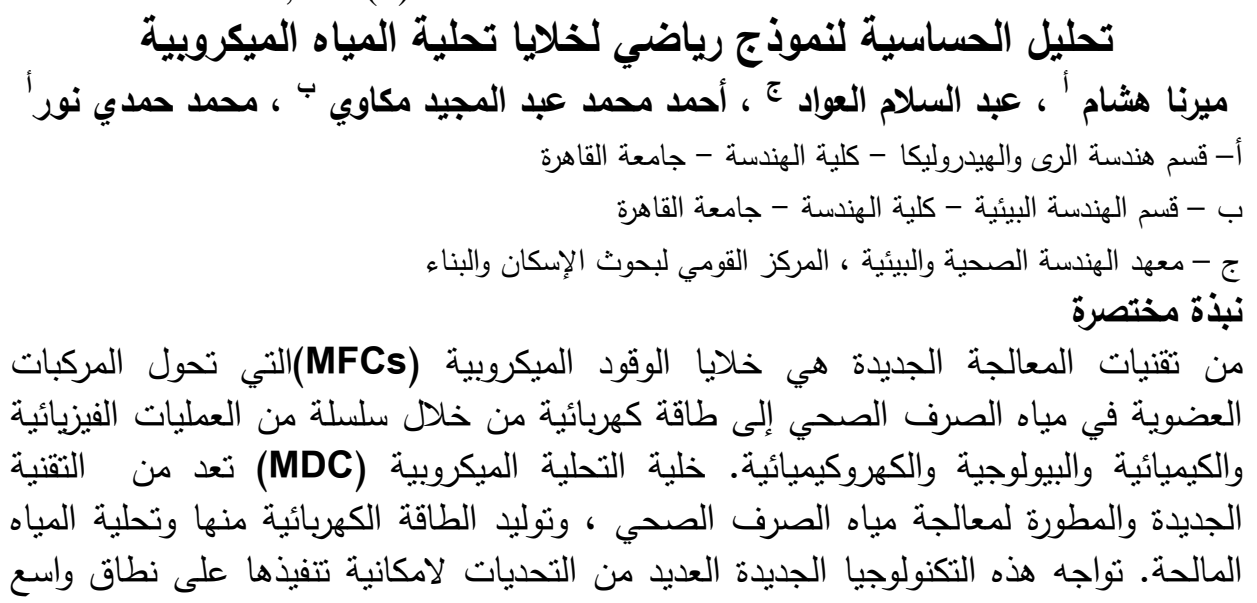




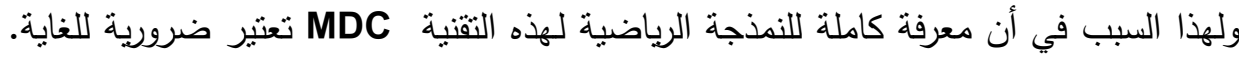

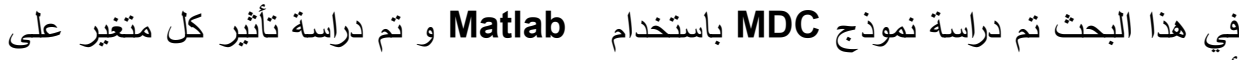

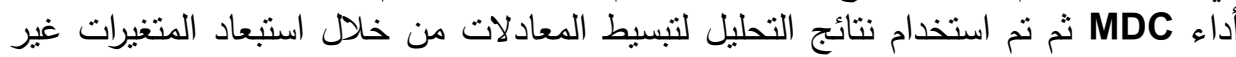
الفعالة. كما تم التحقق من صحة النموذج المخفض لتنفق الدفعات الدورية باستخدام نتائج

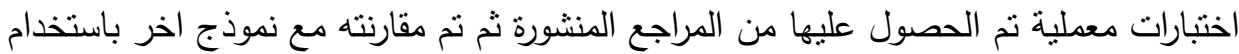

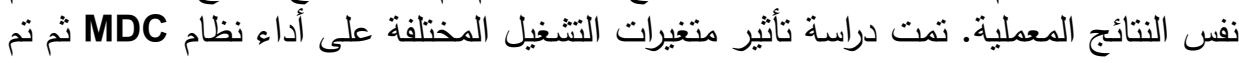
إضافة بعض التعديلات على معادلات النموذج لنتوافق مع الاتجاهات التهات الملاحظة في الإراسات

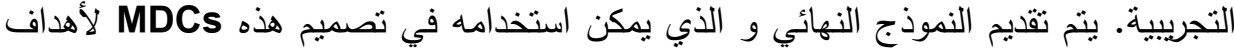
معالجة مختلفة الكلمات الدالة: معالجة مياه الصرف الصحي - تحلية المباه،الطاقة - خلايا الوقود الميكروبية - خلايا التحلية الميكروبية - مياه 